\title{
4-H in the Outdoors: Delivering environmental education to Latino youth in Riverside County
}

\author{
4-H teams up with Project Learning Tree, and kids are the winners.
}

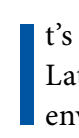
t's a bit of a paradox: Polling indicates that most Latinos in the United States place a high value on environmental conservation (Earthjustice 2015). But Latinos - especially in the younger age brackets tend to participate in outdoor recreation at lower rates than members of other demographic groups (Outdoor Foundation 2017).

It's an imbalance that Claudia Diaz Carrasco decided to do something about.

Diaz, a 4-H youth development advisor, recognized a real need around her home turf of Riverside and San Bernardino counties to provide urban Latino youth with environmental education. But she faced a serious obstacle. Diaz and her 4-H colleagues, she says, are "experts on youth development - not environmental education."

Enter Sandra Derby, the UC ANR-based California coordinator for Project Learning Tree - an international organization that, according to Derby, aims for students "to get outdoors, connect with their own environment, become the drivers of their own learning." Project Learning Tree develops a rich variety of educational curricula, but it doesn't deliver them to students directly. Rather, it trains outside educators, who in turn guide students through Project Learning Tree programs.

If it sounds like a good fit, it was, and collaboration between $4-\mathrm{H}$ and Project Learning Tree soon resulted in a program called $4-\mathrm{H}$ in the Outdoors. "The program was marked for success," Derby says.

The basic mission of $4-\mathrm{H}$ in the Outdoors is to prepare youth in the program to appreciate and safely explore the world outside. In a fairly typical example of the project's work, Stephanie Barrett - a 4-H program representative in Riverside County - led fourth-grade classes at Little Lake Elementary through a process of tree-focused discovery. The youngsters studied tree rings. They "adopted" a tree on school grounds, observing and writing about it. They imagined - and rejected - a world without plants. On a field trip to the nearby Idyllwild Nature Center, they even braved a nature hike. "The program," Barrett says, "is very handson and experimental. It asks kids to think about their own role in the environment. It teaches them how to think - not what to think."

In only its second full year of operation, $4-\mathrm{H}$ in the Outdoors has reached more than 2,000 children. "We're really busy," Barrett says, adding without evident chagrin that "I got home at 11 p.m. two nights this week."

4- $\mathrm{H}$ in the Outdoors has received grants from organizations such as the Southern California Environmental Education Collaborative. Local partners have provided free bus transportation and free admission to nature areas. Mostly, though, the program has benefited from hard work - and from natural synergies between two programs housed within UC ANR.

Project Learning Tree is funded in California by Cal Fire, with support from forestry-based groups such as the Sustainable Forestry Initiative, the parent organization of Project Learning Tree. More information about Project Learning Tree's programs and materials can be found at www.plt.org or ucanr.edu/sites/ PLT_UCCE. CA

-Lucien Crowder

\section{References}

Earthjustice. 2015. National poll finds 78 percent of Latinos say they've directly experienced the effects of climate change. Earthjustice and GreenLatinos. https://earthjustice.org/news/ press/2015/national-poll-finds-78-percent-of-latinos-say-they ve-directly-experienced-the-effects-of-climate-change

Outdoor Foundation. 2017. Outdoor participation report. https:// outdoorindustry.org/wp-content/uploads/2017/05/2017-Outdoor-Recreation-Participation-Report_FINAL.pdf 